\title{
Understanding the Fundamentals of Talent Management for Effective Business Application
}

\author{
Abu Saleh Mohammad Sohel-Uz-Zaman \\ School of Business and Economics, United International University, Dhaka, Bangladesh \\ Email address: \\ sohel@bus.uiu.ac.bd
}

To cite this article:

Abu Saleh Mohammad Sohel-Uz-Zaman. Understanding the Fundamentals of Talent Management for Effective Business Application. International Journal of Economics, Finance and Management Sciences. Vol. 6, No. 3, 2018, pp. 98-103. doi: 10.11648/j.ijefm.20180603.14

Received: March 30, 2018; Accepted: June 6, 2018; Published: June 20, 2018

\begin{abstract}
Organizations irrespective of the nature, sector, and regions, etc. want to attain the sustainable competitive advantage. Unfortunately, in the highly volatile business backdrop, traditional business strategies often fail to bring the desired result as expected. In the search for a new avenue, scholars are showing their keen curiosity towards the value-adding role of human resource. In the knowledge economy, it is believed that human intellect and talent can add value to the business in many ways. Consequently, there is a growing realization that competent and devoted human resource can play an important role in making an organization more effective, i.e. can help an organization to attain its sustainable competitive advantage. As an obvious reason, the concept of talent management could draw considerable attention across the world because of its core philosophy - 'the right people in the right job' which can make an organization efficient and effective. Despite the usefulness of talent management, often organizations express their disappointment that they are finding it difficult to implement this concept fruitfully and reap the benefit of it. From the initial investigation, it is revealed that there are a number of challenges in executing this concept. These are: the absence of a clear and precise definition of talent and talent management, the lack of standardized talent functions and processes, complexity in targeting people in the talent management scheme, aligning talent strategy and formulating a congruent talent strategy, and so on. The core objective of this literary paper is to address these problems as systematically as possible in order to learn the business application of talent management. It is presumed that HR practitioners, managers, business leaders would get a clear picture of it (talent management) and meaningful clues for its application. It is also believed that the discussion of this paper would contribute existing HR literature, too. Data and information have been collected through an extensive literature review, expert interview and personal experience for this exploratory paper.
\end{abstract}

Keywords: Talent Management, Exclusive Perspective, Inclusive Perspective, Talent Strategy, Succession Planning

\section{Introduction}

Achieving sustainable competitive advantage is a common objective of the firms irrespective of nature, sector, size, economy and so on. In the fast changing business environment, traditional business strategies often fail to bring desired benefits as expected. In search for a new means for business success, scholars are increasing expressing their keen interest to explore the value adding role of human resource. In the verge knowledge economy, human intellects and competencies are getting greater attention and it is believed that these can play a vital value adding role in the organizations. Right people at the right job i.e. deploying talented employees can work as a rewarding proposition for the business success. As a result, it has been observed that managing talent is at the top of business discussions in many firms. According to HR academicians and practitioners, talent management is continuing as one of the top priorities in the organization across the world since it can serve as a source of sustainable competitive advantage in the highly dynamic and unpredictable market scenario of the twentyfirst century [1-3]. It has the potential to complement and supplement business strategy. However, quite often organizations express their frustration that they are finding it difficult to apply this concept. From the initial investigation, a number of challenges were revealed and it was also exposed that these challenges are predominantly related to the theoretical underpinning. These are: the lack of a clear 
and precise definition of talent and talent management; no standardized functions and process for talent management; controversy in including people with the talent management program, formulation of a congruent talent strategy and aligning talent strategy with the business strategy, etc. In order to ensure effective implementation of this concept, it is required to address these issues systematically. In this connection, this paper will make an effort to resolve these difficulties in reference to theoretical verdicts of the scholars.

\section{Research Objective and Significance of This Study}

There is a growing consensus that in a rapid changing complex business environment effective talent management can be the key strategy for firm's success and sustainable growth. Despite the potential of talent management, there is doubt to the extent to which this concept is practically implementable. Without having a clear understanding of the fundamentals of talent management it may turn into a catastrophe. In this connection the primary objective of this study is to depict a vivid picture of the concept talent management in terms of its definition, nature, essential functions and process, the people of the scheme, crafting talent strategy and alignment with the business strategy, etc. for its effective business application. In addition, this paper would discuss how talent management is different from traditional human resource management. It is presumed that this paper would provide meaningful guidelines to the HR practitioners, strategists, business leaders, etc. in managing talent in any organization more confidently. At the same time, it is also believed that this study would enrich existing HR literature, too.

\section{Research Methodology}

The qualitative methodology has been adopted for this literary paper. Since this study is involved in comprehending, clarifying and the exposing the essential features of talent management, therefore, the exploratory approach is more appropriate here. Moreover, this approach (exploratory approach) allows to get rich insight on any research topic, too. Multiple sources such as, extensive literature search, interviewing experts and personal experience have been used for data collection and processing. These multiple sources have enhanced data validity and reliability considerably. These multiple sources are also consistent with the exploratory approach. While interviewing the experts, oneto-one in-depth interview technique with the help of unstructured questionnaire was used in order to obtain detailed information on main research topic.

\section{Talent and Talent Management: Definition and Meaning}

In general, the term talent refers to special or gifted skills or abilities that can make a person unique in his/her surroundings. Michaels, Handfield-Jones and Axelrod define talent as the sum of capabilities, innate abilities, skills, wisdom, experience, intellect, acumen, attitude, traits, and motivation of an individual including his or her ability to learn and develop [4]. Ready, Conger and Hill state talents or high potentials are those people who dependably deliver robust outcomes convincingly; who can be proficient in new types of expertise quickly; and they can determine the behaviors which are crucial [5]. Tansley defines talent as "special ability or aptitude, with those seen as talented able to demonstrate outstanding accomplishments in mental and physical domains" [6]. In defining talents the observation of Schuler is of significant and very comprehensive; he states that the individuals who are extraordinary, have capabilities appreciated by the company, behaviors consistent with the company's values, are difficult to find and replace, can create remarkable value to the business, have opportunities to leave at any time, and can help shape the future strategic directions of the business [7]. Naim and Lenka has offered a very clearcut definition of talent management; according to them, talent is highly promising workers who display the capability, involvement, and motivation to succeed in more senior and vital positions [8]. Thus, talent is nothing but those competencies, traits, knowledge, aspiration, drive, behaviors, attitudes, aptitudes and ability to learn and grow of a worker which are needed for the business excellence.

There are a quite a large number of definitions of talent management by highlighting various aspects in it although often these definitions are equivocal and multifarious. From the business application point of view, it is imperative to consider those definitions which are consistent with the main purpose of talent management. Cannon \& McGee define talent management is a method by which an organization identifies, manages and develops its employees now and for the future [9]. Ashton and Morton view talent management as a strategic and holistic approach to both HR and business planning or a new route to organizational effectiveness [10]. Tansley and Tietze comment "Talent management contains strategies and protocols for the systematic attraction, identification, development, retention, and deployment of individuals with high potential who are of particular value to an organization" [11]. It is constituted of enduring procedures that are intended to get the right person in the right job at the right time [12]. By highlighting the continuous supply of talented workers Armstrong and Taylor state that talent management is the process which guarantees talented employees that an organization needs to accomplish its business goals; it is involved in the strategic management of the stream of talent through an organization by developing and maintaining a talent pipeline [13]. From these definitions, it is appeared that talent management is an exclusive approach to managing people along with their inherent competencies, attitudes, aptitudes, aspiration, traits, behaviors, wisdom, experience, etc. in order accomplish organization's goals and guaranteeing required talents as and when necessary, in such a way so that organization can 
become more effective and efficient in attaining its objectives.

\section{Talent Management - Function and Process}

Another important query - what constitutes talent management functions and processes? In order to find the answer, it is required to consider the functional definition of talent management. Lewis and Hackman mention that it is comprised of typical human resource management procedures such as recruitment, selection and career development, and creating a large talent pool by ensuring the quantitative and qualitative flow of employees through the organization [14]. A similar opinion is also expressed by Iles, Preece, and Chuai, they state that it is not fundamentally different from human resource management or human resource development; both (human resource management and talent management) are concerned in finding the right people in the right job at the right time and ensuring the availability of people for the firm [15]. Talent management is an execution of a cohesive, tactical and technology enabled method of HRM, with a specific focus on human resource planning, including employee recruitment, retention, development, and succession planning, preferably for all workers but especially for those who are considered as high potential or in crucial positions [16]. While naming the practices of talent management, Cappelli and Keller, JR indicate it very clearly that it includes the activities like workforce planning, succession planning, employee development, and career management [12]. A corresponding view has been expressed by Chartered Institute of Personnel and Development (CIPD); according to them talent management seeks to attract, pinpoint, develop, involve, retain and employ persons who are recognized as especially valuable to an organization [17]. From these comments, opinions and observations, it can be conceptualized that like human resource management, talent management has certain deliberate activities, e.g. talent planning, role profiling (job description and specification), resourcing, talent development, retaining, rewarding, career planning and succession planning which are designed to maintain required talents for the firm in present as well as for future. Among these activities, talent planning, role profiling, succession planning and career management are the key activities in a talent management scheme since these activities are involved in planning for the required talents, defining required talent in term of competencies and skills, resourcing and assuring a sustainable source of talents, respectively.

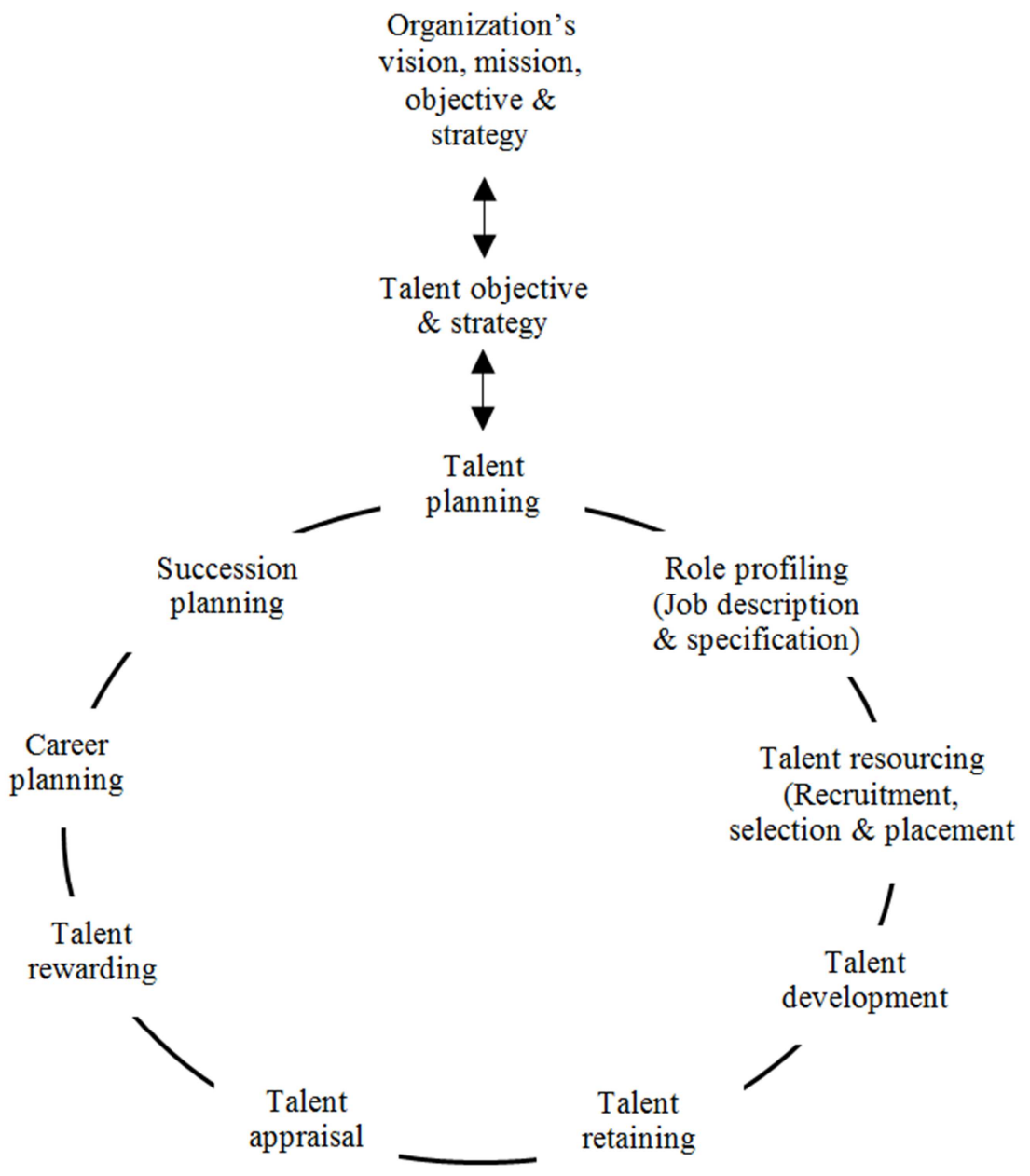

Figure 1. Integrated Talent Management Functions and Processes. 
Talent planning is an indispensable component which is at the heart of talent program. Talent planning is a process by which required talent for the business is determined in terms of number and type for now and in future [13]. All tactical matters like the number and type of talent (talent need analysis); people of the talent program (exclusive or inclusive or both); talent resourcing (internal or external recruitment); selection and placement; performance evaluation procedures, talent nurturing, development and maintenance, mode of rewarding talent; career management and succession planning, etc. are analyzed at this stage with due care in the light of unique organizational context and business plan. According to the directives of talent planning, other talent functions are organized. Another vital component is role profiling. With the help of competency framework, role profile in terms of skills, capabilities, knowledge, duties, responsibilities, and deliverables for each key worker and position is to be prepared. In managing, developing and retaining talents, career management has a very important role. If a firm fails to show a progressive career path to its talented workers sooner or later they will be leaving the organization. Equally, succession planning is also vital in maintaining a talent pool and talent pipeline for the business. Without a carefully designed succession planning, neither will it be possible to find future leaders nor will it be possible to find competent workers for any important job, whenever necessary. In case of other activities like recruitment and selection, training and development, reward and compensation, regular HR tools and techniques can be persuaded. It may be presumed that the process and function of talent management are identical to the traditional human resource management practices. But it is not such. The fundamental difference in between talent functions and traditional HR functions is that in case of talent management, HR functions are customized and dedicated to find, recruit, nurture, maintain and reward, etc. highly potential and promising workers; whereas regular HR functions are planned to administer all the employees irrespective of their ability, importance, hierarchy and positions. Here point to be noted that talent functions and processes must be crafted in consistency with the organization's vision, mission, objective and strategy.

\section{People in Talent Management Program: Exclusive vs. Inclusive Perspective}

Who is included in the talent management scheme perhaps it is the most debatable matter in talent management. In talent management, there are two views or perspectives: exclusive and inclusive. Exclusive perspective believes that not all the employees are equally talented and value adding rather a small number of individuals with high potential are the key value-adding workers in an organization. The exclusive approach has a narrower view and acknowledges that not all workers are talented rather only a few workers are, who provide higher result and have potential and skills for future success [18]. On the other hand, inclusive perspective believes that all employees have innate abilities and skills, thus, they all (all employees) will be nurtured and groomed for the development of the organization. This approach has a wider view and considers that everybody has the ability and potential to demonstrate their skill, and therefore, they should be given equal chance to develop his/her potential to accomplish higher value [8]. Iles and Preece classify three major perspectives (1) Exclusive people - key employees with high performance and/or potential regardless of position. (2) Exclusive position - the right person in the strategically critical jobs or positions. (3) Inclusive people - everyone in the firm is considered as truly or potentially talented and they will be given a fair opportunity and guidance [19]. The first two perspectives i.e. exclusive people and exclusive position of Iles and Preece framework are resemble with the exclusive perspective. Overall, there are two perspectives exclusive and inclusive. In case of exclusive perspective, HR policies, procedures, rules and regulations, etc. are designed for a small but highly skilled and competent workers or key positions of the business. In contrast, in case of inclusive perspective, HR policies and procedures are formulated by considering all the employees in order to bring out the best of each individual in an organization. There is no hard and fast rule which perspective will be persuaded. These two perspectives are not mutually exclusive. Therefore, an organization can opt to follow either the exclusive or inclusive perspective as per its HR strategy. There is an emerging trend of combining both the perspectives. Quite a number of scholars are advocating to pursue a hybrid approach so that organizations can reap the benefit of both the perspectives [20]. According to this hybrid approach, two sets of HR policies and procedures are designed separately by targeting two individual perspectives and implement side by side.

Table 1. Salient Features of Talent Management.

\begin{tabular}{ll}
\hline Objective & $\begin{array}{l}\text { Managing human talents, i.e. human skills, knowledge, } \\
\text { ability, etc. for making organization effective. }\end{array}$ \\
& $\begin{array}{l}\text { It is basically concerned with the small talented section } \\
\text { of the total workforce or few crucial positions in an } \\
\text { Core focus }\end{array}$ \\
& Identify, categorize, nurture and create talent pool for \\
& business success. Talent planning, performance \\
Strategy & appraisal, and talent pool/pipeline are the building \\
& blocks of talent management. \\
& There are two perspectives: exclusive and inclusive. \\
Exclusive perspective refers to the HR policies and \\
practices for few potential employees or critical \\
inveople & positions of an organization. In contrast, inclusive \\
perspective refers to the HR policies and practices for all \\
employees with a belief that every employ has innate \\
ability, skill, and talent which need equal opportunity to \\
grow. \\
Talent planning, recruitment, selection, training and \\
development, performance evaluation, rewarding, career \\
planning and succession planning
\end{tabular}




\section{Talent Management Strategy and Alignment with the Business Strategy}

The undisputed objective of talent management is to assist an organization to become more effective through its people. For that, it is imperative to formulate a good and befitting talent strategy. While commenting on an effective talent strategy Cappelli suggests that it must be capable of addressing and resolving any inconsistency between the supply and demand of talent; he further comments that it should not merely an employee development or succession planning, as these are common focuses of many definitions, instead, it should focus on helping the firm to attain its strategic objectives [21]. Therefore, talent strategy should be in the line of organization's vision, mission, and strategy. It must be formulated by considering the unique organization perspective otherwise it would not be able to serve the business properly. It is should take into account all indigenous factors like organization history and culture, leadership and people management style, decision making process, operating system and so on. In addition, while framing a talent strategy, there are some other several matters which also need proper attention, too. These are: the people of talent management program, resourcing required talents, activities of talent management, nurturing and developing talents, aligning workers' aptitudes with the organization's requirements and so on. Since the socio-economic context of every organization is different, that is why it is impossible to propose a universal or common guideline for crafting talent strategy. Nevertheless, it is possible to recommend a procedure through which it is possible to tailor a consistent talent strategy. These are:

1. Defining overall business strategy.

2. Articulating HR objective.

3. Talent profiling i.e. defining required talents in terms of competencies, attitudes and aptitudes of the workers.

4. Talent gap analysis and talent and resourcing. Here talent gap analysis refers to the mismatch between existing and required talent inventories. In order to mitigate talent gap, talents are to be recruited. Talent resourcing can be done either internally or externally.

5. Determining either to pursue exclusive perspective or inclusive perspective or the both.

6. Designing talent management functions and processes. All the talent management functions must be supporting each other - a congruence among talent functions and processes.

7. Creating a talent pool and a talent succession plan in the light of present and future business objectives and needs.

8. Evaluating talent management program. At this evaluation stage, the output or contribution of human resource and the accomplishment of organization goals are required to me measured in order to assess the effectiveness of talent management program.

The talent management strategy must be rational, result oriented above all consistent with the business. Firms can attain competitive advantage when they embrace a logical, well-grounded and strategic approach to talent management. By managing talent strategically, firms can create an extraordinary performing workplace, inspire to become a learning organization, contribute to their branding schema, and assist in managing diversity [17].

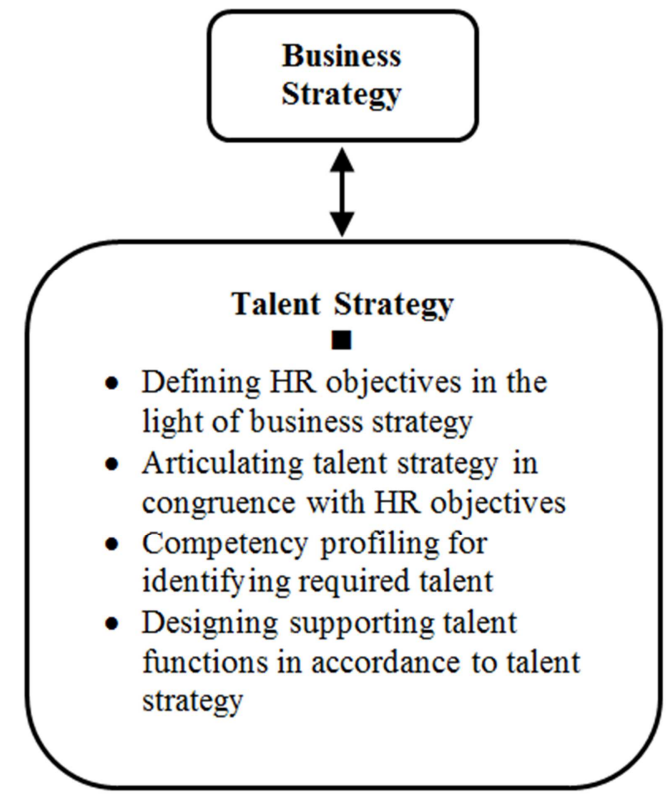

Figure 2. Aligning talent strategy with the business strategy.

\section{Conclusion}

In the era of knowledge economy, human intellect is considered as a very valuable resource of an organization. Talent management is one of the useful techniques of utilizing human intellect for organization effectiveness. It can unleash the potential of workers, faster accomplishment of business objectives, and develop key business competence. As an elementary strategy, talent management tends to pursue, classify and ameliorate skills that will be needed to maintain future competitive advantage [22]. The organization that fosters talent management strategy and practice is more likely prepared to compete efficiently in the highly dynamic complex marketplace. It helps an organization to become competitive by developing essential competencies of its workers. Collings and Mellahi comment that although it is indirect, yet there is a positive relationship with organizational performance and talent management [23]. Talent management aligns HR strategy with the business goals and also integrates other operations by developing a role profile for each job and create a talent culture. It also tries to ensure the right person is in the right job at the right time [24] and assists to execute business strategy. Talent management is a kind of change management from traditional administrative human resource management to contemporary dynamic HR management. This shift is not easy; it needs to create a talent mindset and culture through people oriented leadership, formulating HR driven business strategy and investment in people development, etc. 


\section{References}

[1] Cascio, W. and Boudreau, J. (2016), The search for global competence: from international HR to talent management", Journal of World Business, Vol. 51 No. 1, pp. 103-114.

[2] Meyers, M. and van Woerkom, M. (2014), The influence of underlying philosophies on talent management: theory, implications for practice, and research agenda, Journal of World Business, Vol. 49, No. 2, pp. 192-203.

[3] Vaiman, V., Collings, D. and Scullion, H. (2012), Global talent management: trends, challenges, and opportunities, Management Decision, Vol. 50, No. 5, pp. 925-941.

[4] Michaels, E. G., Handfield-Jones, H. and Axelrod, B. (2001), The War for Talent, Boston, MA: Harvard, Business School Press.

[5] Ready, D. A., Conger, J. A. and Hill, L. A. (2010), Are You a High Potential? Harvard Business Review, Vol. 88, No. 6, pp. 78-84.

[6] Tansley, C. (2011), What do We Mean by the Term "Talent" in Talent Management? Industrial and Commercial Training, Vol. 43 No. 5 , pp. $266-274$.

[7] Schuler, R. S. (2015), The 5-C framework for managing talent, Organizational Dynamics, Vol. 1, No. 44, pp. 47-56.

[8] Naim, M. F. and Lenka, U. (2017), Talent management: a burgeoning strategic focus in Indian IT industry", Industrial and Commercial Training, Vol. 49, No. 4, pp. 183-188.

[9] Cannon, J. A. and McGee, R. (2010), Talent Management and Succession Planning (2nd edition), London: Chartered Institute of Personnel and Development (CIPD).

[10] Ashton, C. and Morton, L., (2005), Managing talent for competitive advantage: Taking a systemic approach to talent management, Strategic HR Review, Vol. 4, No. 5, pp. 28-31.

[11] Tansley, C. and Tietze, S. (2013), Rites of passage through talent management stages: An identity work perspective, International Journal of Human Resource Management, Vol. 24, No. 9, pp. 1799-1815.

[12] Cappelli, P. and Keller, JR (2014), Talent management: Conceptual approaches and practical challenges, Annual Review of Organizational Psychology and Organizational Behavior, Vol. 1(March), pp. 305-331.

[13] Armstrong, M. and Taylor, S. (2014), Armstrong's Handbook of Human Resource Management Practice. London: Kogan Page.

[14] Lewis, R. E. and Hackman, R. J. (2006), Talent Management: A Critical Review, Human Resource Management Review, Vol. 16, No. 2, pp. 139-54.

[15] Iles, P., Preece, D. and Chuai, X. (2010), Talent management as a management fashion in HRD: Towards a research agenda, Human Resource Development International, Vol. 13, Vol. 2, pp. $125-45$.

[16] Hughes, C. J. and Rog, E. (2008), Talent management: a strategy for improving employee recruitment, retention and engagement within hospitality organisations, International Journal of Contemporary Hospitality Management, Vol. 20 No. 7 , pp. 743-57.

[17] CIPD (2017), Factsheet: Talent Management: An overview. London: Chartered Institute of Personnel and Development (CIPD).

[18] Gallardo-Gallardo, E., Dries, N. and González-Cruz, T. F. (2013), What is the meaning of 'talent' in the world of work? Human Resource Management Review, Vol. 23, No. 4, pp. 290-300.

[19] Iles, P. and Preece, D. (2010), Talent management and career development, in (eds) J. Gold, R. Thorpe and A. Mumford, Gower Handbook of Leadership and Management Development, Farnham, Gower, pp. 243-60.

[20] Ford, J., Harding, N. and Stoyanova, D. (2010), Talent Management and Development: An Overview of Current Theory and Practice, Bradford: University of Bradford Management School.

[21] Cappelli, P. (2008), Talent on Demand: Managing talent in an uncertain age, Boston MA: Harvard Business School Press.

[22] Frank, F. D. and Taylor, C. R. (2004), Talent Management: trends that will shape the future, Human Resource Planning, Vol. 27, No. 1, pp. 33-41.

[23] Collings D. G. and Mellahi K. (2009), Strategic talent management: a review and research agenda, Human Resource Management Review, Vol. 19, No. 4, pp. 304-13.

[24] Mondy, R. W. and Martocchio, J. J. (2016), Human Resource Management, Essex: Pearson. 